\title{
The relationship between body mass index and children's presentations to a tertiary pediatric emergency department
}

\author{
Valentina Ferro ${ }^{1}$, Antonella Mosca ${ }^{2}$, Francesca Crea ${ }^{1}$, Maria Alessia Mesturino ${ }^{1}$, Carla Olita', Andrea Vania ${ }^{3}$, \\ Antonino Reale ${ }^{1}$, Valerio Nobili ${ }^{2}$ and Umberto Raucci $^{{ }^{*}}$
}

\begin{abstract}
Background: The child obesity and its complications are associated with an alarming increased health care use, including the emergency department (ED). We evaluated the effects of the obesity and overweight in children admitted to $E D$, especially in patients with injury diagnosis.

Methods: A retrospective study of patients aged 6-18 years was conducted. Patients were categorized into normal weight (body mass index, $\mathrm{BMI}<85$ th); overweight (BMI $\geq 85$ th e $<95$ th); obesity (BMI $\geq 95$ th). Multiple logistic analysis was used for estimation of risk factors associated with the BMI and to explore the association between injury diagnosis and BMI.

Results: The predictive factors associated with obesity and overweight were school age $(p<0.001)$, male gender $(p<0.001)$ and number of visits for year (obesity: $p<0.001$ and overweight: $p<0.05)$. Obese children were less at injury risk than normal weight $(p<0.05)$. In injury subset, fractures in school age were more likely to occur in obesity $(p<0.01)$. Dislocated fractures $(p<0.01)$ and fractures at lower extremity were more likely to occur in obesity and overweight $(p<0.05)$

Conclusions: School age children presenting to ED are more at risk of excess body weight than adolescents and are at higher fracture risk if obese and overweight. This has clear implication to support the efforts to reduce the obesity in childhood. The ED may represent a crucial setting for the early identification of these children and of co-morbidities related $\mathrm{BMI} \geq 85$ th, and for a timely specialist referral of these children, especially if school age.
\end{abstract}

Keywords: Obesity, Overweight, Childhood, Adolescence, Injury, Fracture, Emergency, Body mass index, Prevention

\section{Background}

The worrying increase of obesity and overweight in children, resulting in what is now an epidemic, has drawn a raising attention to the potential short and long-term health consequences. In fact, this phenomenon places a significant burden on healthcare system as evidenced by increased hospital admissions for obesity-related diagnoses, lengthened hospital stay [1], higher medication use [2], and a greater frequency of outpatient clinic visits and emergency department (ED) visits as well [3], and a major use of the ED than primary care settings for

\footnotetext{
* Correspondence: umberto.raucci@opbg.net

'Emergency Pediatric Department, Bambino Gesù Children's Hospital, IRCCS,

Piazza S. Onofrio 4, Rome, Italy

Full list of author information is available at the end of the article
}

routine medical care [4]. The hospital ED is frequently a major source of primary care and it might become a not less important setting for the screening, counseling and prevention of children at excess body weight risk. This is backed up by a previous study that shows parents and their children are interested in receiving education addressing healthier lifestyle choices and they feel that the ED is an appropriate setting for such an intervention program as well [5].

Further to obesity, another crucial challenge for health system is the unintentional injury that represents the leading cause of childhood death and disability involving a huge drain health and societal resources as well [6].

The relationship between obesity and injury is a relatively new and interesting field; most of the results are 
in the direction to draw a link between the overweight/ obesity and the occurrence of injury even if some aspects remain unclear and contradictory [7]. The obesity and injury are two entities not to be considered separately [8], but they may interact with multiple implications on the child outcome and induce the need of enhancing the health surveillance and implement specific plans for child health safety. The aim of study is to describe the characteristics of children admitted to ED in relation to Body Mass Index (BMI) and to investigate the relationship between BMI and injury at ED. Finally, we would emphasize and promote the role of the ED as a strategic setting for screening and counseling, for the early identification of co-morbidities related $\mathrm{BMI} \geq 85 \mathrm{th}$, and for a timely specialist referral of these children.

\section{Methods}

\section{Design study}

A prospective observational study was conducted on patients aged 6-18 years admitted to ED at Children's Hospital Bambino Gesù in Rome during period January 1th and October 31th, 2013. Exclusion criteria were: children aged under 6 years old and BMI $<5$ th percentile, children critically ill and parent of child participant did not consent the study.

The following data were recorded: sex, age, ethnic group, height, weight, waist circumference (WC), triage, symptom onset at admission, the number of visits in ED in the last year, outcome, length of hospital staying and diagnosis.

The age was categorized into two groups: school age (6-12 years) and adolescent (13-18 years).

The weight, height and WC measurements were performance by a health provider (pediatrician, medical resident, nurse) and not included cloths and shoes. The WC was calculated as the average of two measurements at umbilicus by a common meter.

We determined BMI of patients and the percentile, according to the WHO growth charts. Children were grouped into: normal weight $(\mathrm{BMI} \geq 5$ th $\mathrm{e}<85$ th percentile); overweight (BMI $\geq 85$ th $\mathrm{e}<95$ th percentile); obesity ( $\geq 95$ th percentile).

The triage code to identify the severity of clinical condition at admission included: 1) yellow code (very urgent priority), 2) green and white code (urgent and nonurgent condition). The red code was excluded because corresponding to patients critically ill. The diagnoses were reported according to International Classification of Disease, Ninth Revision codes. Nevertheless, by the reason of great dimension of the sample we simplified for univariate and multivariate analysis into two diagnostic categories: a) injury, b) all others.

Then, we selected patients with injury diagnosis. We extracted also the following data. The type injury including: fracture; soft tissue injuries; laceration; strain, sprain, dislocation; concussion; multiple trauma/ other mechanism. Body region injured: head/neck; face; upper extremity; lower extremity; trunk and multiple sites. The injury mechanism: fall/crash at leisure-sport activities; road traffic injury; fall between planes; static and passive mechanism (e.g. crush, electrocution; amputation etc.) and unknown mechanism. The study was approved by the Ethics Committee of the Bambino Gesù Children's Hospital according to the Declaration of Helsinki (as revised in Seoul, Korea, October 2008).

\section{Statistical analysis}

Statistical analysis was performed using the software IBM SPSS (Statistical Package for the Social Sciences) version 24.0. The quantitative variables were described as mean and standard deviation (SD) (normally distributed) or median and interquartile range (not-normally distributed). Categorical variables were described as absolute and relative frequencies. Means were compared with the Student's t-test, and in case of not-normally distributed the Mann Whitney test was used. The Chi-Square test was used to assess the association between categorical variables. Multivariable logistic regression analysis was used for estimation of risk factors associated with the BMI groups and to explore the association between the characteristics of children with injury diagnosis and BMI. The selection of independent variables was done by backward elimination starting with all predictors in the model and remaining the last significant variable for each step. The $p$ value $<0.05$ was considered statistically significant.

\section{Results}

\section{Characteristics associated to BMI in our sample}

From January 1th to October 31th 2013, 60,030 admissions were recorded at our pediatric ED, and of those, 13,267 were children aged 6-18 years old; a total of 265 was excluded because severally ill. Of the remaining sample, 2848 patients were consented to participating study by the parents, but 160 were excluded for having $\mathrm{BMI}<5$ th.

The prevalence of normal weight, overweight and obesity in our cohort was $66.5 \%, 20 \%, 13.5 \%$, respectively.

The characteristics of overall population related to BMI are listed in Table 1.

Males were more frequently obese than other BMI groups $(p<0.001)$ and the school age children were more commonly obese than adolescents compared to other BMI groups $(p<0.001)$.

The causes of admissions to ED are illustrated in Fig. 1. 
Table 1 Characteristics of children admitted to emergency department and bivariate associations between covariates and body mass index

\begin{tabular}{|c|c|c|c|c|c|}
\hline Variable & $\begin{array}{l}\text { Total } \\
n=2688\end{array}$ & $\begin{array}{l}\text { BMI < 85th } \\
n=1787(66.5 \%)\end{array}$ & $\begin{array}{l}\mathrm{BMI} \geq 85 \text { th }-<95 \text { th } \\
n=538 \\
(20 \%)\end{array}$ & $\begin{array}{l}\mathrm{BMI} \geq 95 \text { th } \\
n=363(13.5 \%)\end{array}$ & $P$ value \\
\hline \multicolumn{6}{|l|}{ Age group } \\
\hline School children & 1637 (60.9\%) & $1025(57.4 \%)$ & $352(65.4 \%)$ & $260(71.6 \%)$ & \multirow[t]{2}{*}{$<0.001$} \\
\hline Adolescents & $1051(39.1 \%)$ & $762(42.6 \%)$ & $186(34.6 \%)$ & $103(28.4 \%)$ & \\
\hline \multicolumn{6}{|l|}{ Gender } \\
\hline Male & $1509(56.1 \%)$ & 937 (52.4\%) & $312(58 \%)$ & $260(71.6 \%)$ & \multirow[t]{2}{*}{$<0.001$} \\
\hline Female & 1179 (43.9\%) & $850(47.6 \%)$ & $226(42 \%)$ & $103(28.4 \%)$ & \\
\hline \multicolumn{6}{|l|}{ Ethnic groups } \\
\hline Italian & 2464 (91.7\%) & $1640(91.8 \%)$ & $491(91.3 \%)$ & $333(91.7 \%)$ & \multirow[t]{2}{*}{0.93} \\
\hline Others & $224(8.3 \%)$ & $147(8.2 \%)$ & $47(8.7 \%)$ & $30(8.3 \%)$ & \\
\hline \multicolumn{6}{|c|}{ Symptom onset (days) } \\
\hline$($ mean $\pm S D)$ & $3.81 \pm 7.1$ & 3. $81 \pm 7.2$ & $3.82 \pm 7.3$ & $3.81 \pm 6.3$ & 0.09 \\
\hline \multicolumn{6}{|c|}{ Emergency triage code } \\
\hline Yellow & $141(5.2)$ & $96(5.4 \%)$ & $25(4.6 \%)$ & $20(5.5 \%)$ & \multirow[t]{2}{*}{0.78} \\
\hline Green-White & 2547 (94.8\%) & $1691(94.6 \%)$ & $513(95.4 \%)$ & $343(94.5 \%)$ & \\
\hline \multicolumn{6}{|c|}{ Number of emergency department visits per year } \\
\hline$($ mean $\pm S D)$ & $3.42 \pm 3.74$ & $3.35 \pm 3.475$ & $3.51 \pm .311$ & $3.65 \pm 4.08$ & 0.77 \\
\hline \multicolumn{6}{|c|}{ Abdomen circumference $(\mathrm{cm})$} \\
\hline$($ mean $\pm S D)$ & $73.27 \pm 12.01$ & $69.11 \pm 9.26$ & $77.90 \pm 10.81$ & $86.88 \pm 13.11$ & $<0.001$ \\
\hline \multicolumn{6}{|c|}{ Diagnostic categories } \\
\hline Injury & $746(27.7 \%)$ & $500(27.9 \%)$ & $154(28.6 \%)$ & $92(25.3 \%)$ & \multirow[t]{2}{*}{0.79} \\
\hline All others & $1942(72.3 \%)$ & $1282(72.1 \%)$ & $384(71.4 \%)$ & $271(74.6 \%)$ & \\
\hline \multicolumn{6}{|l|}{ Outcome } \\
\hline Discharge & $2458(91.4 \%)$ & $1637(91.6 \%)$ & $488(90.7 \%)$ & $333(91.7 \%)$ & \multirow[t]{2}{*}{0.78} \\
\hline Hospitalization & $230(8.6 \%)$ & $150(8.4 \%)$ & $50(9.3 \%)$ & $30(8.3 \%)$ & \\
\hline \multicolumn{6}{|c|}{ Length of hospital staying (days) } \\
\hline$($ mean $\pm S D)$ & $0.53 \pm 5.4$ & $0.37 \pm 1.655$ & $1.10 \pm 11.506$ & $0.41 \pm 2.08$ & 0.021 \\
\hline
\end{tabular}

BMI Body Mass Index, SD standard deviation

The multivariable logistic regression analysis (Table 2) showed that school age children were over 23 times significantly more likely to be obese (OR: 23.22; CI: $95 \%$ : 15.60-34.56; $p<0.001)$ and over 5 times to be overweight (OR: 5.17; CI: 95\%: 3.96-6.74; $p<0.001$ ) than adolescents compared to children with normal weight.

Males were significantly over 2-fold at risk to be obese (OR: 2.56; CI: 95\%: $1.86-3.51 ; p<0.001$ ) and $30 \%$ to be overweight (OR: 1.30; CI: 95\%: 1.05-1.61; $p<0.001$ ) respectively than females.

The children with obesity and overweight were more likely to report a major number of visits for year at ED (OR: 1.06; CI: 95\%: 1.02-1.11; $p<0.001$ and OR: 1.04; CI: $95 \%$ : $1.01-1.07 ;<=0.05)$.

The children with obesity were $34 \%$ less likely to present injury compared to patients with normal weight (OR: 0.66; CI: 95\%: 0.47-0.93; $p<0.05$ ).

\section{Association between BMI and injury in children admitted} to ED

In our population, $746(27.7 \%)$ children admitted to ED had a diagnosis of injury. The characteristics of injury subset are reported in Table 3.

The prevalence of the injury was $67 \%, 20.6 \%, 12.3 \%$, in children with normal weight, overweight and obesity respectively. The obese injured patients were more frequently school age $(p=0.007)$ and males $(p=0.007)$. Obese children were hospitalized more than other BMI groups $(p=0.006)$.

The fracture occurred mostly in obese (42.4\%) but not significantly. The dislocated fracture was significantly common in patients with obesity $(18.5 \%)$ than overweight (9.8\%) and normal weight (8.8\%) $(p=0.05)$. Concerning the injury mechanism, the fall/crash at leisure-sport activities occurred more frequently $(66.2 \%)$ 


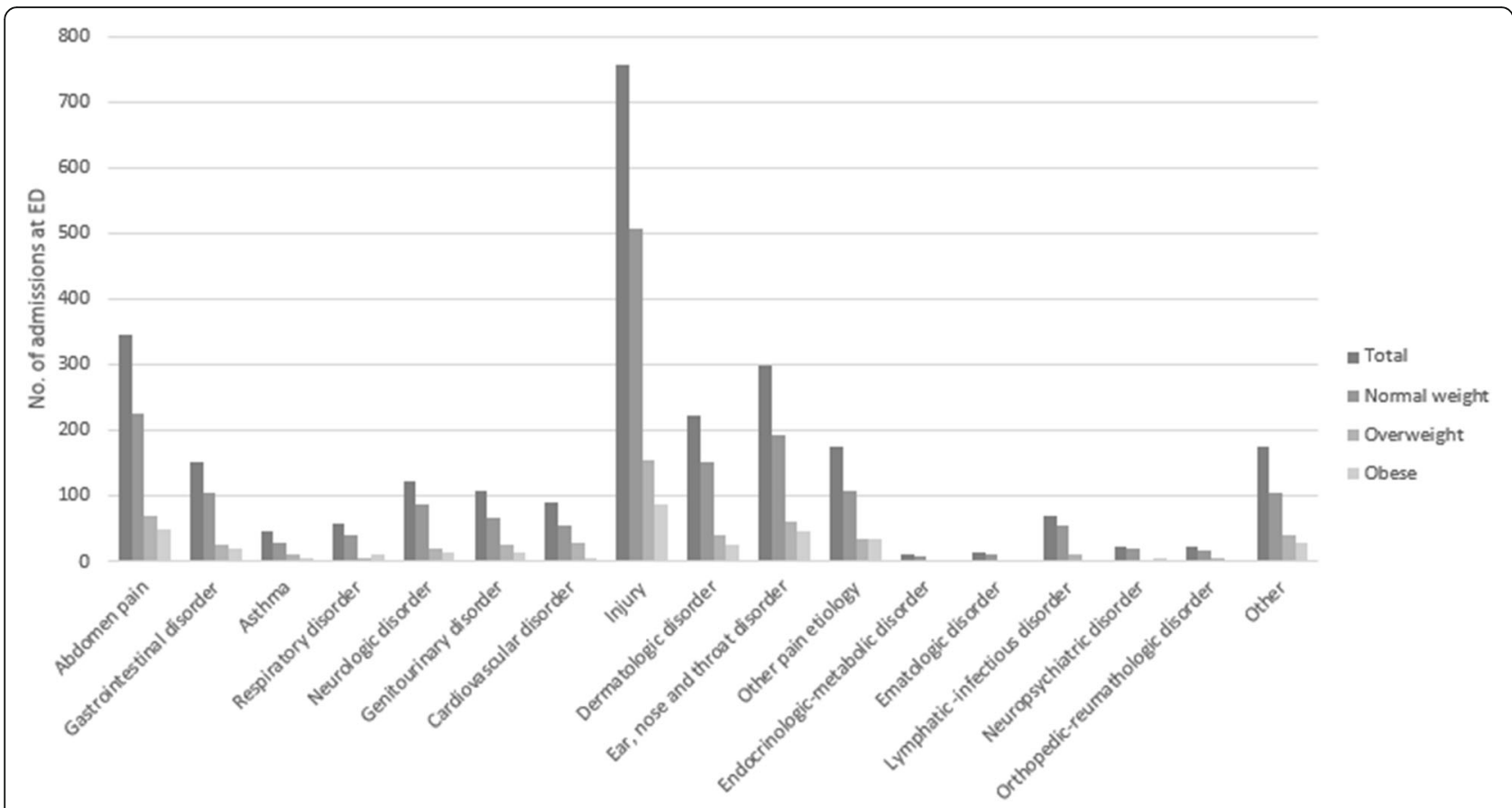

Fig. 1 Distribution of various causes of admission to emergency department related to Body Mass Index groups

and pertained to normal weight children compared to others $(p=0.023)$.

The multivariate analysis exploring the association between the clinical characteristics of the injury subset and the BMI groups is showed in Table 4. The likelihood of being obese increased by over 22 times in school age than adolescents (OR: 22.94; CI: 10.50-50.14; $p<0.001$ ); similarly, school age children were over 6 fold at risk to be overweight than adolescents (OR: 6.45; CI: 95\%: 3.71-10.97; $p<0.001)$. Males had a higher risk to be obese (OR: 2.43; CI: 95\%: 1.26-4.67; $p<0.01$ ). Considering the outcome, obese children were less likely to be discharged (OR: 1.13: CI: $0.12-0.73 ; p<0.01$ ). The static and passive mechanism was over 3 fold more likely to

Table 2 Logistic regression analysis for predictive factors of obesity and overweight in children admitted to emergency department

\begin{tabular}{|c|c|c|c|c|c|c|}
\hline \multirow[t]{2}{*}{ Variable } & \multicolumn{3}{|c|}{$\begin{array}{l}\text { Obese (BMI } \geq 95 \text { th) } \\
\text { vs Normal weight }{ }^{a}\end{array}$} & \multicolumn{3}{|c|}{$\begin{array}{l}\text { Overweight ( } \geq 85 \text { th- }<95 \text { th) } \\
\text { vs Normal weight }{ }^{a}\end{array}$} \\
\hline & $\beta$ & OR & $95 \% \mathrm{Cl}$ & $\beta$ & $\mathrm{OR}$ & $95 \% \mathrm{Cl}$ \\
\hline \multicolumn{7}{|l|}{ Age group } \\
\hline School children & $3.14^{* * *}$ & 23.22 & $15.60-34.56$ & $1.64^{* * *}$ & 5.17 & $3.96-6.74$ \\
\hline Adolescents & - & 1 & & - & 1 & \\
\hline \multicolumn{7}{|l|}{ Gender } \\
\hline Male & $0.94^{* * *}$ & 2.56 & $1.86-3.51$ & $0.26^{* * *}$ & 1.30 & $1.05-1.61$ \\
\hline Female & - & 1 & & - & 1 & \\
\hline Abdomen circumference $(\mathrm{cm})$ & $0.22^{* * *}$ & 1.25 & $1.23-1.27$ & $0.13^{* * *}$ & 1.13 & $1.12-1.15$ \\
\hline Number of emergency department visits per year & $0.06^{* *}$ & 1.06 & $1.02-1.11$ & $0.04^{*}$ & 1.04 & $1.01-1.07$ \\
\hline \multicolumn{7}{|l|}{ Diagnostic category } \\
\hline Injury & $-0.41^{*}$ & 0.69 & $0.49-0.96$ & -0.14 & 0.87 & $0.68-1.10$ \\
\hline Other diagnosis & - & 1 & & - & 1 & \\
\hline Length of hospital staying (days) & 0.03 & 1.03 & $0.97-1.09$ & 0.04 & 1.04 & $0.99-1.09$ \\
\hline
\end{tabular}

OR Odd ratio, BMI Body Mass Index, $\mathrm{Cl}$ Confidence interval

${ }^{*} p<0.05$

$* * p<0.01$

*** $p<0.001$

${ }^{\text {a }}$ The reference category in the multinomial logistic model is those with normal weight (BMI 5th-85th) 
Table 3 Characteristics of injury subset at emergency department and bivariate associations between covariates and body mass index

\begin{tabular}{|c|c|c|c|c|c|}
\hline Variable & $\begin{array}{l}\text { Total } \\
n=746\end{array}$ & $\begin{array}{l}\mathrm{BMl}<85 \text { th } \\
n=500 \\
(67 \%)\end{array}$ & $\begin{array}{l}\text { BMI } \geq 85 \text { th-95th } \\
n=154 \\
(20.6 \%)\end{array}$ & $\begin{array}{l}\text { BMI } \geq 95 \text { th } \\
n=92 \\
(12.3 \%)\end{array}$ & $P$ value \\
\hline \multicolumn{6}{|l|}{ Age group } \\
\hline School children & $466(62.5 \%)$ & $293(58.6 \%)$ & $106(68.8 \%)$ & $67(72.8 \%)$ & \multirow[t]{2}{*}{0.007} \\
\hline Adolescent & $280(37.5 \%)$ & 297 (41.4\%) & $48(31.2 \%)$ & $25(27.2 \%)$ & \\
\hline \multicolumn{6}{|l|}{ Gender } \\
\hline Male & $452(60.6 \%)$ & $288(57.6 \%)$ & $95(61.7 \%)$ & $69(75 \%)$ & \multirow[t]{2}{*}{0.007} \\
\hline Female & 294(39.4\%) & $212(42.4 \%)$ & $59(38.3 \%)$ & $23(25 \%)$ & \\
\hline \multicolumn{6}{|l|}{ Emergency triage code } \\
\hline Yellow & $685(91.8 \%)$ & $469(93.8 \%)$ & $145(94.2 \%)$ & $84(91.4 \%)$ & \multirow[t]{2}{*}{0.61} \\
\hline Green-White & $61(8.2 \%)$ & $31(6.2 \%)$ & $9(5.8 \%)$ & $8(8.7 \%)$ & \\
\hline \multicolumn{6}{|l|}{ Abdominal Circumference $(\mathrm{cm})$} \\
\hline$($ mean $\pm S D)$ & $73.88 \pm 12,13$ & $70.05 \pm 9.65$ & $78.64 \pm 10.97$ & $86.73 \pm 14.38$ & $<0.001$ \\
\hline \multicolumn{6}{|l|}{ Outcome } \\
\hline Discharge & $685(91.8 \%)$ & $468(93.6 \%)$ & 140 (90.9\%) & 77 (83.7\%) & \multirow[t]{2}{*}{0.006} \\
\hline Hospitalization & $61(8.2 \%)$ & $32(6.4 \%)$ & $14(9.1 \%)$ & $15(16.3 \%)$ & \\
\hline \multicolumn{6}{|l|}{ Length of hospital stay (days) } \\
\hline$($ mean $\pm S D)$ & $0.31 \pm 1.4$ & $0.27 \pm 1.21$ & $0.3 \pm 1.08$ & $0.6 \pm 1.56$ & 0.78 \\
\hline \multicolumn{6}{|l|}{ Injured body region } \\
\hline Head/neck & $46(6.2 \%)$ & $33(6.6 \%)$ & $9(5.8 \%)$ & $4(4.3 \%)$ & \multirow[t]{6}{*}{0.08} \\
\hline Face & $55(7.4 \%)$ & $38(7.6 \%)$ & $15(9.7 \%)$ & $2(2.2 \%)$ & \\
\hline Upper extremity & $385(51.6 \%)$ & $257(51.4 \%)$ & 79 (51.3\%) & $49(53.3 \%)$ & \\
\hline Lower extremity & $206(27.6 \%)$ & 135 (27.0\%) & $42(27.3 \%)$ & $29(31.5 \%)$ & \\
\hline Trunk & $48(6.4 \%)$ & $33(6.6 \%)$ & $8(5.2 \%)$ & $7(7.6 \%)$ & \\
\hline Multiple site & $6(0.8 \%)$ & $4(0.8 \%)$ & $1(0.6 \%)$ & $1(1.1 \%)$ & \\
\hline \multicolumn{6}{|l|}{ Types of injuries } \\
\hline Fracture & $260(34.9 \%)$ & $173(34.6 \%)$ & $48(31.2 \%)$ & $39(42.4 \%)$ & \multirow[t]{6}{*}{0.13} \\
\hline Contusion/abrasion & $282(37.7 \%)$ & 195 (39.0\%) & $62(40.3 \%)$ & $24(26.1 \%)$ & \\
\hline Sprain/strain/dislocation & $108(14.5 \%)$ & $66(13.2 \%)$ & $25(16.2 \%)$ & $17(18.5 \%)$ & \\
\hline Laceration & $42(5.6 \%)$ & $28(5.6 \%)$ & $8(5.2 \%)$ & $6(6.5 \%)$ & \\
\hline Concussion & $31(4.2 \%)$ & $23(4.6 \%)$ & $6(3.9 \%)$ & $2(2.2 \%)$ & \\
\hline Multiple trauma/other mechanism & $24(3.2 \%)$ & $15(3 \%)$ & $5(3.2 \%)$ & $4(4.3 \%)$ & \\
\hline \multicolumn{6}{|l|}{ Injury mechanism } \\
\hline Fall/crash at leisure-sport activities & $494(66.2 \%)$ & $335(67 \%)$ & 100 (64.9\%) & $59(64.1 \%)$ & \multirow[t]{5}{*}{0.023} \\
\hline Road traffic injury & $16(2.1 \%)$ & $9(1.8 \%)$ & $4(2.6 \%)$ & $3(3.3 \%)$ & \\
\hline Fall between planes & $27(3.6 \%)$ & $22(4.4 \%)$ & $4(2.6 \%)$ & $1(1.1 \%)$ & \\
\hline Static and passive mechanism & $31(4.2 \%)$ & $31(4.2 \%)$ & $3(1.9 \%)$ & 10(10.9\%) & \\
\hline Unknown mechanism & $78(23.9 \%)$ & 116 (23.2\%) & $43(27.9 \%)$ & $19(20.7 \%)$ & \\
\hline \multicolumn{6}{|l|}{ Fracture Location } \\
\hline Lower extremity & $44(16.9 \%)$ & $27(15.6 \%)$ & $7(14.6 \%$ & $10(25.6 \%)$ & \multirow[t]{3}{*}{0.21} \\
\hline Upper extremity & 199(76.5\%) & 134 (77.5\%) & $37(77.1 \%)$ & $28(71.8 \%)$ & \\
\hline Other & $17(6.5 \%)$ & $12(6.9 \%)$ & $4(8.3 \%)$ & $1(2.6 \%)$ & \\
\hline Dislocated Fracture & $76(10.2 \%)$ & $44(8,8 \%)$ & $15(9.8 \%)$ & $17(18.5 \%)$ & 0.019 \\
\hline
\end{tabular}


Table 4 Logistic regression analysis for predictive factors of obesity and overweight in injured patients

\begin{tabular}{|c|c|c|c|c|c|c|}
\hline \multirow[t]{2}{*}{ Variable } & \multicolumn{3}{|c|}{$\begin{array}{l}\text { Obese (BMI } \geq 95 \text { th) } \\
\text { vs Normal weight }\end{array}$} & \multicolumn{3}{|c|}{$\begin{array}{l}\text { Overweight }(\geq 85 \text { th- }<95 \text { th) } \\
\text { vs Normal weight }{ }^{\mathrm{a}}\end{array}$} \\
\hline & $\beta$ & OR & $95 \% \mathrm{Cl}$ & $\bar{\beta}$ & OR & $95 \% \mathrm{Cl}$ \\
\hline \multicolumn{7}{|l|}{ Age group } \\
\hline School age & $3.13^{* * *}$ & 22.94 & $10.50-$ & $1.87^{* * *}$ & 6.45 & $3.71-10.97$ \\
\hline Adolescents & - & 1 & 50.14 & - & 1 & \\
\hline \multicolumn{7}{|l|}{ Gender } \\
\hline Male & $0.89^{* *}$ & 2.43 & $1.26-4.67$ & 0.29 & 1.34 & $0,88-2,05$ \\
\hline Female & - & 1 & & - & 1 & \\
\hline Abdomen circumference $(\mathrm{cm})$ & $0.21^{* * *}$ & 1.23 & $1.20-1.27$ & $0.120^{* * *}$ & 1.13 & $1.10-1.16$ \\
\hline \multicolumn{7}{|l|}{ Injury mechanism } \\
\hline Fall/crash at leisure-sport activities & 0.64 & 1.07 & $0.61-1.86$ & -0.22 & 0.80 & $0.53-1.21$ \\
\hline Road traffic injury & 0.70 & 2.02 & $0.50-8.13$ & 0.17 & 1.20 & $0.35-4.06$ \\
\hline Fall between planes & -1.30 & 0.27 & $0.03-2.16$ & -0.72 & 0.49 & $0.16-1.49$ \\
\hline Static and passive mechanism & $1.12^{* *}$ & 3.36 & $1.35-8.38$ & -1.21 & 0.30 & $0.07-1.33$ \\
\hline Unknown mechanism & - & 1 & & - & 1 & \\
\hline \multicolumn{7}{|l|}{ Outcome } \\
\hline Discharge & $-1.23^{* *}$ & 0.29 & $0.12-0.73$ & -0.43 & 0.65 & $0.31-1.37$ \\
\hline Hospitalization & - & 1 & & - & 1 & \\
\hline \multicolumn{7}{|l|}{ Injury and age group } \\
\hline Fracture in school age & $0.90 * *$ & 2.46 & $1.28-4.74$ & 0.271 & 1.32 & 0.752 .37 \\
\hline Other injuries in school age & & 1.81 & $0.97-3.38$ & $0.67^{* *}$ & 1.95 & $1.21-3.15$ \\
\hline Fracture in adolescents & 0.59 & 1.26 & $0.53-2.99$ & 0.29 & 1.34 & $0.70-2.60$ \\
\hline Other injuries in adolescents & $0.23-$ & 1 & & - & 1 & \\
\hline \multicolumn{7}{|l|}{ Injury and body region } \\
\hline Fracture at upper extremity & 0.43 & 1.54 & $0.76-3.13$ & 0.43 & 0.91 & $0.53-1.59$ \\
\hline Other injuries at upper extremity & 0.23 & 1.26 & $0.69-2.65$ & 0.23 & 1.13 & $0.66-1.95$ \\
\hline Fracture at lower extremity & $1.01^{*}$ & 2.73 & $1.08-6.92$ & $1.01^{*}$ & 0.86 & $0.34-2.17$ \\
\hline Other injuries at lower extremity & 0.26 & 1.30 & $0.61-2.80$ & 0.26 & 1.07 & $0.62-1.88$ \\
\hline Fracture at other body regions & $-4,86$ & 0.61 & $0.07-5.13$ & $-4,86$ & 1.10 & $0.33-3.68$ \\
\hline Other injuries at other body regions & - & 1 & & - & 1 & \\
\hline \multicolumn{7}{|l|}{ Type fracture } \\
\hline Dislocated fracture & $1.14^{*}$ & 3.13 & $1.16-8.48$ & 0.47 & 1.59 & $0.74-3.43$ \\
\hline Compound fracture & - & 1 & & - & 1 & \\
\hline
\end{tabular}

OR Odd ratio, BMI Body Mass Index,CI Confidence interval

${ }^{*} p<0.05$

${ }^{* *} p<0.01$

$* * * p<0.001$

${ }^{\text {a }}$ The reference category in the multinomial logistic model is those with normal weight (BMI 5th-85th)

occur in the group of the obesity (OR: 3.36; CI: $1.35-$ 8.38; $p<0.01$ ).

The fracture in school age group was over 2-fold more likely to involve obese children (OR: 2.46; CI: $1.28-4.78$; $p$ $<0.01$ ). The odds of reporting a fracture at lower extremity for children with obesity were over twice than normal weight (OR: 2.73; CI: 1.08-6.92; $p<0.05$ ); similarly, children with overweight were $20 \%$ more at risk to report a fracture at lower extremity (OR: 0.86; CI: 0.34-2.17; $p<0.05$ ).
The dislocated fracture was over 3-fold more likely to occur in obese and overweight (OR: 3.13; CI: 1.16-8.48; $p<0.01)$.

\section{Discussion}

In our study, the prevalence of overweight and obesity was reported to be $20.2 \%$ and $13.5 \%$ respectively. The regional (Lazio) data from national surveillance obesity system shows a prevalence of overweight and obesity 
respectively $21.7 \%$ and $9.4 \%$ in 2014 [9]. Our data derived from the ED admissions of a tertiary hospital, although not representative of the Lazio region, and therefore not comparable, show high levels still worrying of excess of weight body in children.

Concerning epidemiological aspects, school age children were significantly more likely to be obese or overweight than adolescents. The early childhood is a key window period for delivering potentially effective preventive interventions because these years are a period of sensitivity to environmental influences and for the imprinting of health lifestyle [10]. Moreover, the excess of body weight in younger children is a highly predictive of obesity during adolescence and adulthood [11, 12]. Males were at a higher risk to be obese and overweight than females. This finding is in line with national and regional data [9]. No difference was showed between Italian and children with different ethnic background in contrast with a previous study conducted in Emilia Romagna Region in which the obesity resulted to be higher among Immigrants [13]. Probably in our region children from immigrant families abandon increasingly the originating eating habits to assimilate those of the host country [14]. The obese and overweight children were more likely to report a major number of visits for year at ED than patients with normal weight. Some studies have reported that excess body weight disorders involve an increased health care utilization, including ED visits ${ }^{1}$ for both acute and routine medical care [4]. This phenomenon might be due to increase of obesity related comorbidities and consequently implicates a growing burden on healthcare system [15]. Nevertheless, this finding might to be due to confounding factors such as the family and social class that we did not considered in our analysis. Although in different settings from the one where we carried out our research and with weak association measures, some researcher reported that adjusting for demographics, socio-economic status, and chronic medical conditions, overweight or obese children still more frequently utilize the ED and outpatient clinic visits than under/healthy weight children [16]. Regarding causes of admission to ED, obese children were $34 \%$ less likely to present an injury. The possible relationship between obesity and injury is a relatively new interesting area of study, although the research in this area is limited for children. An association between obesity and various types of injury is described such as head and chest injuries in motor vehicle crashes [17], musculoskeletal injuries [18], ankle injuries [19], lower extremities [8]. Probably in our study children with $\mathrm{BMI} \geq 85$ th were less likely to report an injury because of the type of involved injury mechanism. In fact, the fall/crash leisure-sport activities occurred more frequently in normal weight whereas the passive and static mechanism occurred mostly in BMI group $\geq 95$ th. The static and passive mechanism occurred mostly in obese children. These findings might indicate that normal weight children were exposed to a higher injury risk because of a major physical activity.

Among different types of injury, the fracture in school age individuals was over twice more likely if obese. There are few potential explanations for this data. First, age-related variation in mobility patterns should be considered. In fact, physical activity decreases with advancing age during childhood [20], because older children spend more time in sedentary behaviors including screen based (i.e. TV/video viewing, playing $\mathrm{PC} /$ video games etc.) and not screen based (i.e. texting, talking on the phone, etc.) [21], in particular overall sedentary time and individual sedentary behaviors increase during the transition from primary/middle to secondary/high school [22]. Finally, adolescents with obesity are supposed to present an increased bone density, similar to the pattern seen in obese adults [23].

Among different types of injury, the fracture occurred mostly in obese children but not significantly.

Children with obesity and overweight were more likely at risk for fracture at lower extremity $(p<0.05)$. This finding is in line with other studies that show the association between childhood obesity and increased risk of lower extremity fracture [23]. We might explain this finding by interaction of different potential factors. Firstly, the mechanical effect involves the overloading of bones, joints and soft tissues of the locomotor system on lower extremity influencing the alignment, structure, function of the hip, knee and foot [24], and consequently making more vulnerable the bone and joint of lower extremity to a potential risk of fracture and osteoarthritis [25]. Secondly, biomechanical factors might be considered, such as effects of excess body weight on the walking gait. In fact, children with excess weight disorders report a slower habitual or self-selected walking speeds with a concomitant reduction in step length and step frequency [26]. Thus, the reduced walking speed is typified by longer single support and double support phase durations along with a shorter swing phase [27]. The consequence of excess mass in children is an increase in both the absolute amount of force applied to the joint and the muscular force needed to move the additional mass during ambulation [27]. All these mechanical and biomechanical factors potentiate the effect of obesity on decreased bone density [28]. The bone density not only is affected by reduced physical activity or by bone development that is overtaxed by rapidly increasing weight [28], but we suppose that the vitamin D deficiency might play a decisive role in the pathogenesis of lower extremity fracture in children with $\mathrm{BMI} \geq 85$ th. A previous cross-sectional study, carried out in our tertiary 
care center for obesity at Children's Hospital Bambino Gesù, reports the vitamin D levels are inversely associated with nonalcoholic steatohepatitis and fibrosis in children with nonalcoholic fatty liver disease [29] that is a complication in children with obesity. Since this is the exclusive experience of a tertiary center, we might presume that children enrolled in this study might present characteristic similar to our cohort because both of them belong to the same hospital's catchment area. This hypothesis might represent a powerful stimulus for a future cross sectional study in order to detect the potential rule of vitamin $\mathrm{D}$ in children with excess weight disorders presenting to our hospital with the lower extremity fracture.

A series of limitations should be considered in our study. First, as this study was carried out in a tertiary care center, its findings may not be extended to the general population. Second, the anthropometric parameters were measured by health providers instructed but we did not consider the error margin of measurement determined by the experience of the providers and by the compliance of the patient. Third, we did not consider chronic or underlying diseases and ongoing therapeutic treatments, thus we cannot exclude this potential confounder.

\section{Conclusion}

Our results indicate that school age children presenting to ED are more at risk of obesity and overweight than adolescents. Although obese children are less at risk of injury, probably because less prone to leisure-sport activities than normal weight counterpart, fractures occur more frequently in school age children with obesity. The childhood is a crucial temporal window for implementation of effective prevention strategy and to avoid future complications. Therefore, the ED might be a strategic setting for in the initial screening of these children and parental counseling, and for a timely specialist referral of these children, especially if school age, in order to guarantee further weight control-related interventions.

\section{Abbreviations}

BMI: Body Mass Index; Cl: Confidence Interval; ED: Emergency Department: OR: Odd Ratio; SD: Standard Deviation; WC: Waist Circumference

\section{Acknowledgements}

Not applicable

\section{Funding}

Not applicable

\section{Availability of data and materials}

The datasets used and/or analyzed during the current study are available from the corresponding author on reasonable request.

\section{Authors' contributions}

UR conceived and designed the study, revised the manuscript critically for important intellectual content. VF analyzed and interpreted data, was involved in revising it critically for important content. AM was involved in the analysis and interpretation of data, in drafting the manuscript. FC was involved in the acquisition of data, in the drafting the manuscript. MAM contributed to the patient enrollment and assessment of literature. CO contributed to the patient enrollment and assessment of literature. AV contributed to the study design and paper editing. AR contributed to the study design and paper editing. VN conceived and designed the study, revised the manuscript critically for important intellectual content. All authors read and approved the final manuscript.

Ethics approval and consent to participate

The study was approved by the Ethics Committee of the Bambino Gesù Children's Hospital according to the Declaration of Helsinki (as revised in Seoul, Korea, October 2008).

Consent for publication

Not applicable

\section{Competing interests}

The authors declare that they have no competing interests.

\section{Publisher's Note}

Springer Nature remains neutral with regard to jurisdictional claims in published maps and institutional affiliations.

\section{Author details}

${ }^{1}$ Emergency Pediatric Department, Bambino Gesù Children's Hospital, IRCCS, Piazza S. Onofrio 4, Rome, Italy. ${ }^{2}$ Hepato-Metabolic Disease Unit, Bambino Gesù Children's Hospital, IRCCS, Rome, Italy. ${ }^{3}$ Centre for Pediatric Dietetics and Nutrition, Department of Pediatrics and Pediatric Neuropsychiatry Rome "Sapienza" University, Rome, Italy.

Received: 12 December 2017 Accepted: 9 March 2018

Published online: 20 March 2018

References

1. Fleming-Dutra KE, Mao J, Leonard JC. Acute care costs in overweight children: a pediatric urban cohort study. Child Obes. 2013;9:338-45. https:// doi.org/10.1089/chi.2012.0134.

2. Solmi F, Morris S. Association between childhood obesity and use of regular medications in the UK: longitudinal cohort study of children aged 5-11 years. BMJ Open. 2015;5:e007373. https://doi.org/10.1136/bmjopen-2014007373

3. Turer $\mathrm{CB}$, Lin H, Flores G. Health status, emotional/behavioral problems, health care use, and expenditures in overweight/obese US children/ adolescents. Acad Pediatr. 2013;13:251-8. https://doi.org/10.1016/j.acap. 2015.08.009.

4. Bianchi-Hayes J, Calixte R, Huang J, Cataldo R, Wong A, Pati S. Healthcare utilization by obese and overweight children. J Pediatr. 2015;166:626-31.e2. https://doi.org/10.1016/j.jpeds.2014.11.044

5. Haber JJ, Atti S, Gerber LM, Waseem M. Promoting an obesity education program among minority patients in a single urban pediatric emergency department (ED). Int J Emer Med. 2015;8:38. https://doi.org/10.1186/s12245015-0086-z.

6. Sethi D, Towner E, Vincenten J, Segui-Gomez M, Racioppi F. European report on child injury prevention: World Health Organization (WHO) European Region; 2008. http://www.euro.who.int/_data/assets/pdf_file/ 0003/83757/E92049.pdf. Accessed 13 Oct 2016

7. Brown CV, Neville AL, Salim A, Rhee P, Cologne K, Demetriades D. The impact of obesity on severely injured children and adolescents. J Pediatr Surg. 2006:41:88-91.

8. Pomerantz WJ, Timm NL, Gittelman MA. Injury patterns in obese versus non obese children presenting to a pediatric emergency department. Pediatrics. 2010;125:681-5. https://doi.org/10.1542/peds.2009-2367.

9. Nardone P, Spinelli A, Buoncristiano, M., Lauria, L, Pizzi E, Andreozzi S, Galeone D. II Sistema di sorveglianza OKkio alla SALUTE: risultati 2014. 2016. http://www.iss.it/binary/publ/cont/ONLINE_Okkio.pdf. Accessed 21 Oct 2016.

10. Baidal JAW, Taveras EM. Childhood obesity: shifting the focus to early prevention. Arch Pediatr Adolesc Med. 2012;166:1179-81. https://doi.org/10. $1001 / 2013$. 
11. Koning M, Hoekstra T, de Jong E, Visscher TL, Seidell JC, Renders CM. Identifying developmental trajectories of body mass index in childhood using latent class growth (mixture) modelling: associations with dietary, sedentary and physical activity behaviors: a longitudinal study. BMC Public Health. 2016;16:1128-39.

12. Nader PR, O'Brien M, Houts R, Bradley R, Belsky J, Crosnoe R, et al. Identifying risk for obesity in early childhood. Pediatrics. 2006;118:e594-601.

13. Toselli S, Zaccagni L, Celenza F, Albertini A, Gualdi-Russo E. Risk factors of overweight and obesity among preschool children with different ethnic background. Endocrine. 2015;49:717-25. https://doi.org/10.1007/ s12020-014-0479-4.

14. Ebenegger V, Marques-Vida PM, Nydegger A, Laimbacher J, Niederer I, Bürgi F. Independent contribution of parental migrant status and educational level to adiposity and eating habits in preschool children. Eur J Clin Nutr. 2011:65:210-8. https://doi.org/10.1038/ejcn.2010.248.

15. Trasande L, Chatterjee $S$. The impact of obesity on health service utilization and costs in childhood. Obesity (Silver Spring). 2009;17:1749-54. https://doi. org/10.1038/oby.2009.67.

16. Lynch BA, Finney Rutten LJ, Jacobson RM, Kumar S, Elrashidi MY, Wilson PM, et al. Health care utilization by body mass index in a pediatric population. Acad Pediatr. 2015;15:644-50. https://doi.org/10.1016/j.acap.2015.08.009.

17. Kim JE, Hsieh MH, Shum PC, Tubbs RS, Allison DB. Risk and injury severity of obese child passengers in motor vehicle crashes. Obesity (Silver Spring). 2015;23:644-52. https://doi.org/10.1002/oby.21018.

18. Finkelstein EA, Chen H, Prabhu M, Trogdon JG, Corso PS. The relationship between obesity and injuries among U.S. adults. Am J Health Promot. 2007; 21:460-8.

19. Zonfrillo MR, Seiden JA, House EM, Shapiro ED, Dubrow R, Baker MD, et al. The association of overweight and ankle injuries in children. Ambul Pediatr. 2008:8:66-9. https://doi.org/10.1016/j.ambp.2007.08.003.

20. lannotti RJ, Kogan MD, Janssen I, Boyce WF. Patterns of adolescent physical activity, screen-based media use, and positive and negative health indicators in the U.S. and Canada. J Adolesc Health. 2009;44:493-9. https:// doi.org/10.1016/j.jadohealth.2008.10.142

21. Pate RR, Mitchell JA, Byun W, Dowda M. Sedentary behaviour in youth. Br J Sports Med. 2011;45:906-13. https://doi.org/10.1136/bjsports-2011-090192.

22. Pearson N, Haycraft E, Johnston J P, Atkin AJ. Sedentary behaviour across the primary-secondary school transition: a systematic review. Prev Med. 2017:94:40-7. https://doi.org/10.1016/j.ypmed.2016.11.010.

23. Kessler J, Koebnick C, Smith N, Adams A. Childhood obesity is associated with increased risk of most lower extremity fractures. Clin Orthop Relat Res. 2013;471:1199-207. https://doi.org/10.1007/s11999-012-2621-z.

24. Wearing SC, Hennig EM, Byrne NM, Steele JR, Hills AP. Musculoskeletal disorders associated with obesity: a biomechanical perspective. Obes Rev. 2006a;7:239-50.

25. Wearing SC, Hennig EM, Byrne NM, Steele JR, Hills AP. The impact of childhood obesity on musculoskeletal form. Obes Rev. 2006 b;7:209-18.

26. McGraw B, McClenaghan BA, Williams HG, Dickerson J, Ward DS. Gait and postural stability in obese and nonobese prepubertal boys. Arch Phys Med Rehabil. 2000:81:484-9.

27. Hills AP, Parker AW. Gait characteristics of obese pre-pubertal children: effects of diet and exercise on parameters. Int J Rehabil Res. 1991;14:348-9.

28. Shultz SP, Anner J, Hills AP. Paediatric obesity, physical activity and the musculoskeletal system. Obes Rev. 2009;10:576-82. https://doi.org/10.1111/j. 1467-789X.2009.00587.x.

29. Nobili V, Giorgio V, Liccardo D, Bedogni G, Morino G, Alisi A, et al. Vitamin D levels and liver histological alterations in children with nonalcoholic fatty liver disease. Eur J Endocrinol. 2014;170:547-53. https://doi.org/10.1530/EJE13-0609.

\section{Submit your next manuscript to BioMed Central and we will help you at every step:}

- We accept pre-submission inquiries

- Our selector tool helps you to find the most relevant journal

- We provide round the clock customer support

- Convenient online submission

- Thorough peer review

- Inclusion in PubMed and all major indexing services

- Maximum visibility for your research

Submit your manuscript at www.biomedcentral.com/submit
Biomed Central 